\title{
Medical management of meningioma in the era of precision medicine
}

\author{
Saksham Gupta, BA, Wenya Linda Bi, MD, PhD, and lan F. Dunn, MD \\ Center for Skull Base and Pituitary Surgery, Department of Neurosurgery, Brigham and Women's Hospital, Harvard Medical
} School, Boston, Massachusetts

\begin{abstract}
Surgery is curative for most meningiomas, but a minority of these tumors recur and progress after resection. Initial trials of medical therapies for meningioma utilized nonspecific cytotoxic chemotherapies. The presence of hormone receptors on meningioma ushered in trials of hormone-mimicking agents. While these trials expanded clinical understanding of meningioma, they ultimately had limited efficacy in managing aggressive lesions. Subsequent detection of misregulated proteins and genomic aberrancies motivated the study of therapies targeting specific biological disturbances observed in meningioma. These advances led to trials of targeted kinase inhibitors and immunotherapies, as well as combinations of these agents together with chemotherapies. Prospective trials currently recruiting participants are testing a diverse range of medical therapies for meningioma, and some studies now require the presence of a specific protein alteration or genetic mutation as an inclusion criterion. Increasing understanding of the unique and heterogeneous nature of meningiomas will continue to spur the development of novel medical therapies for the arsenal against aggressive tumors.

https://thejns.org/doi/abs/10.3171/2018.1.FOCUS17754
\end{abstract}

KEY WORDS meningioma; personalized therapy; targeted inhibitors; immunotherapy; clinical trial

$\mathrm{M}$ ENINGIOMAS are the most common primary central nervous tumors in adults, comprising more than a third of all brain tumors. Most are WHO grade I, while $15 \%-20 \%$ are considered high grade (WHO grade II or III). While grade I meningiomas largely express an indolent course, high-grade meningiomas are associated with poor prognoses: 10-year overall survival (OS) ranges from 53\%-79\% for patients with WHO grade II lesions to $14 \%-34 \%$ for those with grade III tumors. Patients with meningioma refractory to conventional surgery or radiation have limited pharmacotherapeutic options. ${ }^{72}$

Clinical trials for meningioma are challenged not only by a dearth of targets, but also by several qualities of the tumor's growth pattern and epidemiology. First, the relatively indolent nature of WHO grade I meningiomas and the wide variability in the natural history of grade II meningiomas challenge our ability to define consistent outcome measures within a reasonable time frame. The amount of time necessary to reflect true disease control or progression may exceed that budgeted for a typical clinical trial. Second, the relative efficacy of surgery and adjuvant radiation for meningiomas constrains the burden of progressive meningiomas, especially WHO grade I subtypes, which might be studied in clinical trials. These constraints have frequently prompted the accrual of tumors of different grades and with prior treatments into the same trial to allow sufficient power for the end points, which may then confound the interpretation of results.

Additionally, approaches for measuring meningioma growth vary across studies of tumor progression, with some investigators utilizing maximum diameter; others, maximum area; and still others, three-dimensional volumetric analysis. The lack of consistent clinical end points across studies has limited comparisons between trials and raised calls for standardization of trial techniques.

Medical management of meningioma has continued to

ABBREVIATIONS AKT = alpha serine/threonine-protein kinase; EGFR = epidermal growth factor receptor; OS = overall survival; PDGF = platelet-derived growth factor; PFS = progression-free survival; PFS6 = PFS at 6 months; TGF = tumor growth factor; VEGF = vascular endothelial growth factor.

SUBMITTED December 1, 2017. ACCEPTED January 15, 2018.

INCLUDE WHEN CITING DOI: 10.3171/2018.1.FOCUS17754. 
evolve in the last 2 decades, mirroring the expansion of therapeutic strategies in human cancers. Studies of nonspecific agents have given way to trials that leverage our understanding of specific molecular alterations and the immune environment. These discoveries have motivated trials of novel molecular inhibitors and immunotherapies. In the present review, we summarize the medical management strategies studied for meningioma to date and avenues for future therapeutic development in light of biological insights.

\section{Cytotoxic Chemotherapy}

Cytotoxic chemotherapy has generally been reserved for meningiomas refractory to both surgery and radiotherapy (Table 1). A cyclophosphamide, doxorubicin, and vincristine regimen for anaplastic meningioma had modest results despite severe toxicities, with the majority of recipients displaying a stable radiological response and median OS of 5.3 years. ${ }^{9}$ Irinotecan, a topoisomerase I inhibitor, and temozolomide, a DNA alkylator, resulted in $6 \%$ and $0 \%$ progression-free survival (PFS) at 6 months (PFS6), respectively, for refractory WHO grade I meningioma in phase II trials..$^{14,15}$

Hydroxyurea, a ribonucleotide reductase inhibitor, offered initial promise in a small case series in which a positive radiographic response was demonstrated in 3 of 4 recurrent meningioma patients who had received the drug. ${ }^{64}$ Further retrospective and prospective studies of hydroxyurea revealed that patients most commonly display a stable response, followed by progressive disease, and that median PFS on hydroxyurea ranges from 2 to 77 months depending on the study population. ${ }^{10,13,29,40,48,62,74}$

Subsequent clinical trials that assessed the safety and efficacy of combination therapies that included hydroxyurea are discussed further in Combinatorial Pharmacological Therapies below.

\section{Hormone-Directed Therapy}

Meningioma has been associated with the dysregulation of a number of hormonal axes. Hormone exposure has been implicated in the development of meningioma as evidenced by a female preponderance among patients, tumor growth during pregnancy, and the risk reduction seen in menopause and after oophorectomy.

Tamoxifen, an anti-estrogen agent, did not demonstrate efficacy in two phase II trials, with the majority of patients developing progressive disease. ${ }^{23,47}$ In contrast, the anti-progesterone agent mifepristone was associated with modest positive responses in a minority of patients in several retrospective and prospective single-arm trials. ${ }^{25,26}$ These results motivated a phase III randomized controlled trial assessing the impact of mifepristone on OS and PFS in progressive or recurrent meningioma. ${ }^{33}$ While no statistical differences were found between the two treatment arms, the low patient enrollment prevented stratification by tumor grade. Moreover, meningiomas of different grades may differentially express sex hormone receptors and may have obscured potentially salient results from this trial.

Meningiomas demonstrate activation of the growth hormone $(\mathrm{GH})$ /insulin-like growth factor 1 (IGF-1) axis. The
GH/IGF-1 axis is endogenously inhibited by somatostatin, motivating the study of somatostatin analogs in trials. Meningiomas preferentially express somatostatin receptor type 2 (SST2), which can bind the hormone octreotide to decrease cell proliferation. ${ }^{24}$ Response to octreotide is correlated to high SST and Merlin levels in vitro. ${ }^{24}$

An initial retrospective analysis on the efficacy of the somatostatin analog octreotide as therapy for 3 refractory meningioma cases suggested its potential to maintain stable disease..$^{19}$ Additionally, a retrospective study of octreotide in 8 progressive WHO grade I meningiomas demonstrated $100 \%$ PFS at 48 months. ${ }^{65}$ However, other phase II trials that recruited higher proportions of patients with grade II-III meningiomas demonstrated a median PFS ranging from 4 to 5 months. ${ }^{34,68}$

A phase II trial of pasireotide, another somatostatin analog formulation, showed possible therapeutic benefit in high-grade meningioma. ${ }^{55}$ Notably, patients with high-grade meningioma, all of whom had undergone prior surgery and radiotherapy and most of whom had received chemotherapy, had a median OS of 2.0 years. Radiolabeled $\left[\mathrm{DOTA}^{0}, \mathrm{Tyr}^{3}\right]$-octreotide (DOTATOC) therapy, which targets somatostatin receptors, was tested in a phase II trial and demonstrated stable disease in a majority of progressive meningioma cases and a mean OS of 8.6 years from the initiation of treatment; however, the tumor grade distribution was not reported in this study. ${ }^{46}$

\section{Non-Hormonal Targeted Therapies}

The molecular specificity of targeted therapies differentiates them from traditional chemotherapy in providing precise attacks on protein targets. Current therapies act on a range of cellular receptors, signal transduction molecules, cell cycle regulators, and other vital molecules that were initially identified by aberrant protein expression. Targeted therapy for meningioma will necessitate foundational knowledge of these interrelated mechanisms. Antagonists of these pathways have been trialed in meningioma and are discussed below (Table 2).

\section{Vascular Endothelial Growth Factor}

Aberrant angiogenesis is a shared characteristic and therapeutic target in many cancers. Vascular endothelial growth factor (VEGF) is a potent activator of angiogenesis with expression levels that correlate with meningioma grade..$^{43}$ It is also associated with phenotypic characteristics including peritumoral edema and necrosis. ${ }^{22,43}$ Vascular endothelial growth factor signaling further cross-talks with platelet-derived growth factor (PDGF) signaling, another process that has been explored in the treatment of refractory meningiomas, as discussed below..$^{45}$

Targeted anti-angiogenic therapy is a promising avenue for meningioma because of robust pharmaceutical development and VEGF expression in meningioma. In two recent retrospective case series, bevacizumab, a monoclonal antibody against VEGF-A, has shown efficacy in maintaining stable disease in meningiomas refractive to multiple treatment modalities. ${ }^{45,52}$ In one of these studies, bevacizumab led to a median PFS of 17.9 months and PFS6 of $85.7 \%$ among 14 patients with WHO grade I-III 
密要员

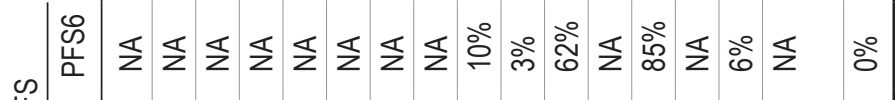

땀

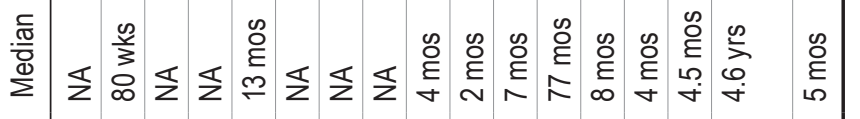

-

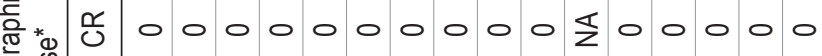

을

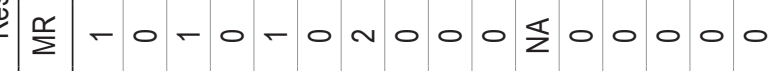

कि - क

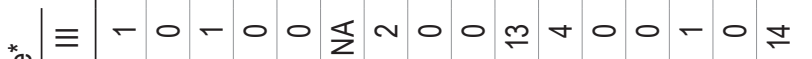

票=

우 - m느유

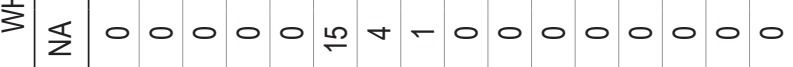

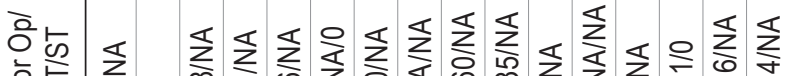

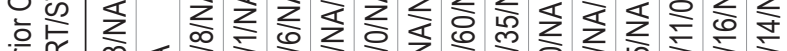

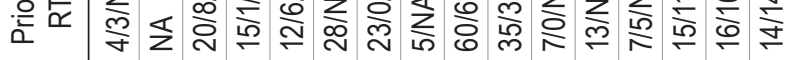

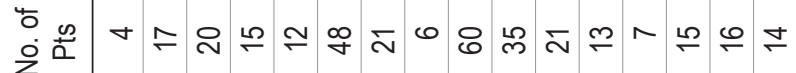

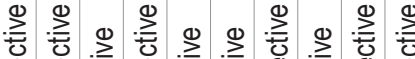

咅

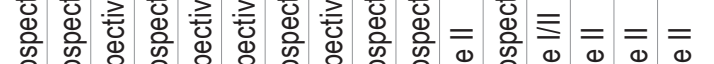

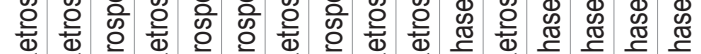

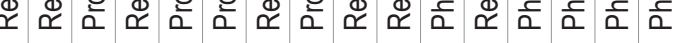
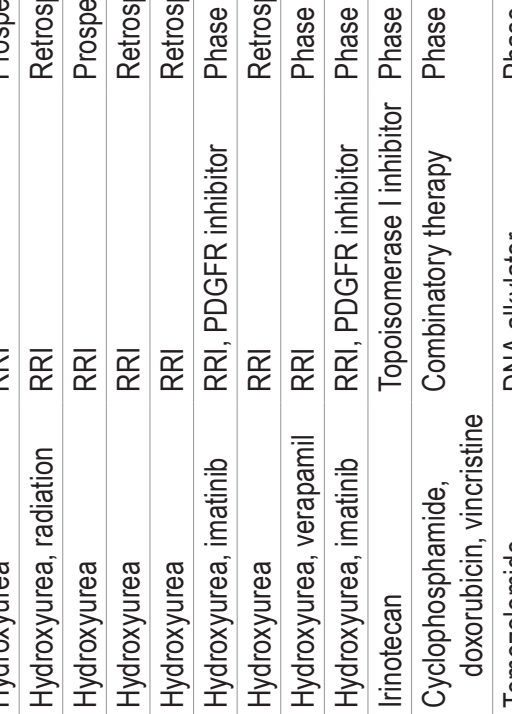

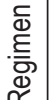
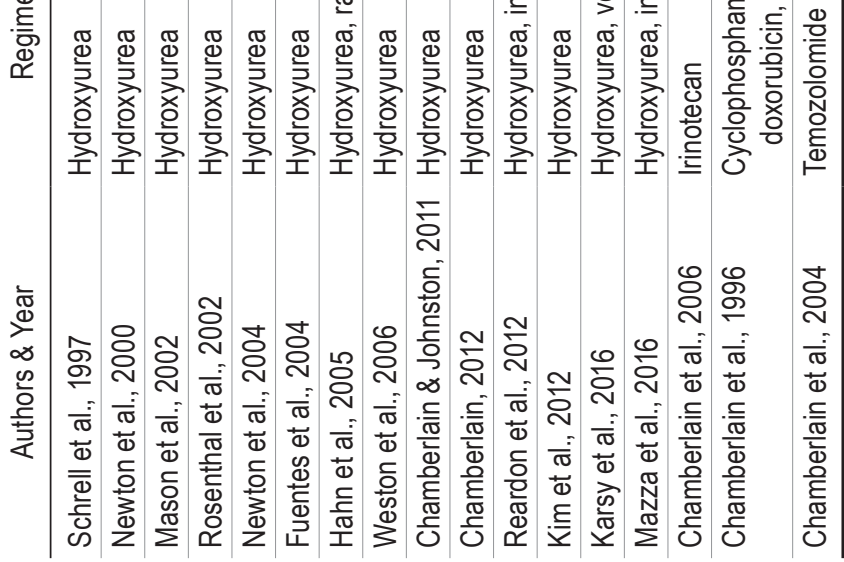

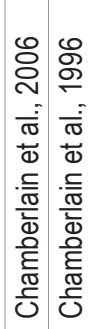

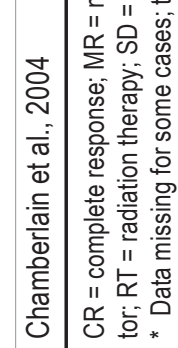




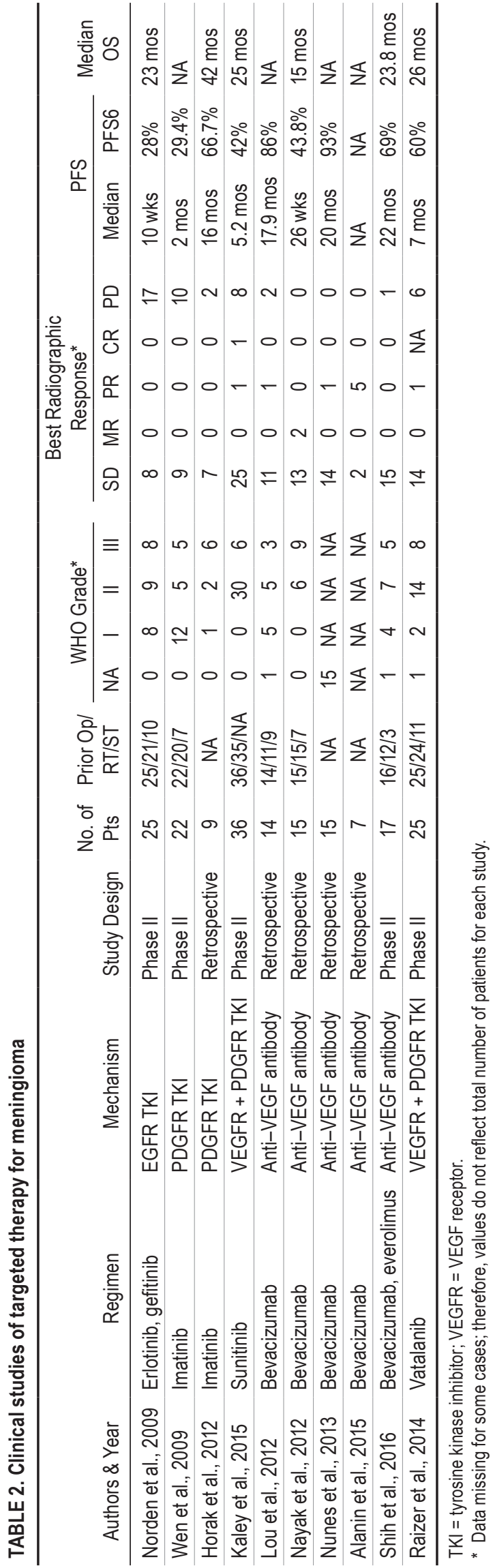

meningiomas. ${ }^{45} \mathrm{~A}$ retrospective review of bevacizumab for NF2-associated vestibular schwannomas and meningiomas revealed a radiographic response, defined as at least $20 \%$ volumetric shrinkage, in $29 \%$ of the meningiomas for a median duration of 3.7 months. ${ }^{56}$ These responses were generally short-lived, however, as median PFS was 15 months.

\section{Platelet-Derived Growth Factor}

Models of meningioma highlight the important role of PDGF in tumor development and transformation. Antibodies against PDGF variants inhibit meningioma growth in vitro, and the induction of PDGF $\beta$ expression in mouse arachnoid is sufficient to generate meningioma. ${ }^{58,69}$ The expression level of certain PDGF and PDGF receptor (PDGFR) subtypes correlates with tumor grade. ${ }^{75}$ The PDGFR inhibitor regorafenib has shown increased survival in in vivo testing using an orthotopic mouse model. ${ }^{70}$ Imatinib mesylate inhibits PDGFR as well as c-Kit and $\mathrm{c}-\mathrm{Abl}$, rendering the drug a potential treatment for refractory meningioma. A phase II trial testing imatinib showed modest results, however, with more cases demonstrating radiological progression rather than stable disease..$^{73} \mathrm{~A}$ retrospective case series of tumors with positive immunohistological staining for PDGFR demonstrated a median PFS and PFS6 of 16 months and 66.7\%, respectively. ${ }^{32}$

Sunitinib is a multi-targeted receptor tyrosine kinase inhibitor with activity against the receptors for both VEGF and PDGF and reduces meningioma cell DNA synthesis, viability, and migration in vitro. ${ }^{3}$ A phase II trial of sunitinib for high-grade meningioma refractory to surgery and radiotherapy yielded a median PFS of 5.2 months and median OS of 25 months. ${ }^{38}$ Of interest, a case report on sunitinib for a recurrent, rapidly growing WHO grade II skull base meningioma documented a marked reduction of tumor volume that caused cerebrospinal fluid leakage..$^{59}$ Vatalanib is another multi-targeted receptor tyrosine kinase inhibitor that has exhibited modest therapeutic efficacy in a phase II trial for refractory meningioma; grade II cases in the trial had a 7-month median PFS and 26-month median OS. ${ }^{60}$

\section{Epidermal Growth Factor}

Epidermal growth factor (EGF) and the EGF receptor (EGFR) represent other therapeutic targets. Higher expression levels are associated with benign meningiomas. ${ }^{51} \mathrm{~A}$ phase II trial of erlotinib or gefitinib, two targeted EGFR inhibitors, for recurrent meningioma demonstrated a median PFS of 10 weeks and PFS6 of $28 \% .^{63}$ The limited efficacy of EGFR inhibitors may be partially explained by differing EGFR expression levels of the trial participants.

\section{Other Pathways}

Other pathways involved in cellular growth, cell cycle regulation, transcriptional regulation, and apoptosis have been implicated in meningioma tumorigenesis and growth. Tumor growth factor (TGF) $\alpha$ expression is associated with recurrence and is negatively associated with survival. ${ }^{44}$ Expression of TGF $\beta$ increases activity of the SMAD signaling pathway. ${ }^{35}$ In addition, the expression of 
TGF $\beta$ receptor III is associated with higher-grade meningioma. ${ }^{36}$

Cyclins and cyclin-dependent kinases (CDKs) regulate cell cycle progression and contribute to the hallmark overproliferation associated with cancer. Cyclin D1 expression is associated with an increased tumor grade and recurrence in meningioma. ${ }^{16} \mathrm{~A}$ screen for compounds to identify in vitro tumor growth inhibitors identified silvestrol as an inhibitor that putatively acts through cyclin downregulation that induces $\mathrm{G} 2 / \mathrm{M}$ cell cycle arrest. ${ }^{57}$

Histone deacetylase (HDAC) inhibitors exert cytostatic effects on replicating cells by hyper-acetylating DNA. The HDAC inhibitor AR-42 induces meningioma apoptosis in vitro. ${ }^{8}$ It has also caused tumor regression in a xenograft mouse model of meningioma. ${ }^{8} \mathrm{~A}$ truncated form of tumor necrosis factor-related apoptosis-inducing ligand (TRAIL) that cannot initiate apoptotic signaling is correlated with meningioma grade. ${ }^{42}$

\section{Molecularly Targeted Therapies From Genomic Analyses}

Next-generation sequencing technology has yielded insights into potential oncogenic drivers of meningioma. Identified mutations include $A K T 1, S M O, K L F 4, T R A F 7$, PIK3CA, SUFU, BAPI, SMARCBI/E, POL2RA, and others, in addition to the well-characterized NF2., ${ }^{1,17,66}$ Screening tumors prior to adjuvant therapy may improve the tailoring of individual regimens and trial stratification. BAPl mutations highlight additional benefits of genomic screening, including those for possible syndromic patients.

\section{PI3K/AKT/mTOR Pathway}

The phosphoinositol-3 kinase (PI3K) pathway transduces growth factor signals and is upregulated in many cancers. Activation of PI3K leads to the phosphorylation and activation of alpha serine/threonine-protein kinase (AKT), which directly activates mammalian target of rapamycin (mTOR). AKT1 and PI3KCA mutations were identified in $9 \%$ and $7 \%$ of meningiomas, respectively, which are largely WHO grade I tumors., ${ }^{1,2850}$ AKT1-mutant meningiomas demonstrate a proclivity for the anterior fossa skull base (19\%).

$A K T 1$ mutations, observed nearly exclusively in nonNF2 altered tumors, have generated particular excitement due to the presence of inhibitors currently in clinical trial. A case of metastatic, highly refractory meningioma that demonstrated ex vivo AKT inhibitor sensitivity had stable disease up to 1 year after initiating AKT inhibitor therapy with AZD5363. ${ }^{71}$ The role of AKT1 inhibition in the treatment of recurrent or progressive meningioma is currently in clinical trial (see below).

\section{SMO}

Mutations in SMO have been detected in about $6 \%$ of non-NF2 altered meningiomas, with the majority of $S M O$ altered tumors found at the skull base, particularly at the olfactory groove ${ }^{6,17} \mathrm{Up}$ to $28 \%$ of olfactory groove meningiomas harbor $S M O$ mutations, and this molecular signature may also portend a poorer prognosis among WHO grade I olfactory groove tumors. ${ }^{6}$ A phase II trial is underway to explore the efficacy of SMO inhibition in recurrent or progressive meningioma.

\section{BAP1}

Breast cancer type 1 susceptibility protein (BRCA1)associated protein-1 (BAP1) is a tumor suppressor that acts via deubiquitinase activity on nucleosomes, and $B A P I$ inactivating mutations have been identified in meningiomas with rhabdoid morphology ${ }^{66} \mathrm{BAPl}$-mutant meningiomas have been found to be at least WHO grade II and clinically aggressive. The presence of $B A P I$ mutations confers an elevated risk for multiple types of cancer, so knowledge of their expression could modify an individual's tumor screening and surveillance. Enhancer of zeste homolog 2 (EZH2) inhibitors and their homologs have demonstrated in vitro inhibition of BAP1-mutant mesotheliomas, which have elevated EZH2 mRNA levels. The EZH2 inhibitor tazemetostat is currently undergoing clinical trial in BAP1-deficient relapsed or refractory malignant mesothelioma (NCT02860286, http://www.clinicaltrials.gov). Enhancer of zeste homolog 2 is similarly upregulated in high-grade meningioma and may present an opportunity for targeted inhibition. ${ }^{31}$

\section{Immunotherapy}

Immunotherapy in refractory meningioma dates to initial experiences with interferon (IFN)- $\alpha$ after it was shown to reduce meningioma growth by $70 \%-100 \%$ in vitro. ${ }^{41} \mathrm{~A}$ phase II pilot study testing IFN- $\alpha$ on 6 recurrent meningioma cases showed a positive response to treatment with stable disease or a slight regression. ${ }^{37}$ Another phase II trial on $35 \mathrm{WHO}$ grade I meningiomas refractory to surgery, radiation, and chemotherapy demonstrated a favorable median PFS of 7 months and PFS6 of 54\%.12 A similar trial on high-grade meningiomas demonstrated a median PFS of only 3 months and PFS6 of $17 \% .^{11}$

Despite these initially grim results, several lines of evidence support a role for immunotherapy in meningioma. ${ }^{5}$ First, these tumors recruit immune populations, especially monocytes and cytotoxic T cells, with higher concentrations of macrophages in higher-grade tumors. ${ }^{27}$ Second, half of the mutations found in meningioma are predicted to be neo-antigenic with a higher number observed in high-grade tumors. ${ }^{4}$ Third, meningiomas exist outside the blood-brain barrier and may be modulated by the systemic immune response. Fourth, and most salient for therapeutics, high-grade meningiomas with higher expressions of the immune checkpoint markers programmed cell death protein 1 (PD-1) and PD-1 ligand (PD-L1) are associated with worse survival, independent of tumor grade, extent of resection, and prior recurrence. ${ }^{30}$ Programmed cell death protein 1 is a cell surface receptor on $\mathrm{T}$ cells and binds PD-L1 on antigen-presenting cells and tumors cells to inhibit T-cell activation. Antibodies directed against the PD-1/PD-L1 axis strengthen the immune response and have achieved objective responses in several cancers. Anaplastic meningioma cells highly express PD-L1, suggesting that anti-PD-1/PD-L1 inhibitors may offer clinical efficacy for these tumors. 
TABLE 3. Active, enrolling trials of medical therapies for meningioma registered on clinicaltrials.gov

\begin{tabular}{|c|c|c|c|c|c|c|}
\hline Official Study Title & Drug & Phase & $\begin{array}{c}\text { No. of } \\
\text { Participants }\end{array}$ & Sponsor & $\begin{array}{l}\text { Completion } \\
\text { Date }\end{array}$ & $\begin{array}{l}\text { Trial } \\
\text { Registration } \\
\text { No. }\end{array}$ \\
\hline $\begin{array}{l}\text { Exploratory Evaluation of AR-42 } \\
\text { Histone Deacetylase Inhibitor } \\
\text { in the Treatment of Vestibular } \\
\text { Schwannoma and Meningioma }\end{array}$ & AR-42 & 0 & 20 & $\begin{array}{l}\text { Massachusetts Eye and Ear Infirmary, } \\
\text { Johns Hopkins University, Mayo Clinic, } \\
\text { Stanford University, Ohio State Univer- } \\
\text { sity, Nationwide Children's Hospital }\end{array}$ & $\begin{array}{r}\text { August } \\
2018\end{array}$ & NCT02282917 \\
\hline $\begin{array}{l}\text { Combination of Everolimus and } \\
\text { Octreotide LAR in Aggressive } \\
\text { Recurrent Meningiomas }\end{array}$ & $\begin{array}{l}\text { Everolimus, } \\
\text { octreotide }\end{array}$ & II & 20 & $\begin{array}{l}\text { Assistance Publique Hopitaux de Mar- } \\
\text { seille }\end{array}$ & $\begin{array}{c}\text { January } \\
2018\end{array}$ & NCT02333565 \\
\hline $\begin{array}{l}\text { Ribociclib (LEE011) in Preoperative } \\
\text { Glioma and Meningioma Patients }\end{array}$ & Ribociclib & $0 / I 1$ & 48 & St. Joseph's Hospital and Medical Center & $\begin{array}{l}\text { December } \\
2018\end{array}$ & NCT02933736 \\
\hline $\begin{array}{l}\text { A Study of Nivolumab in Adult } \\
\text { Participants With Recurrent } \\
\text { High-Grade Meningioma }\end{array}$ & Nivolumab & II & 25 & Dana-Farber Cancer Institute & $\begin{array}{r}\text { August } \\
2018\end{array}$ & NCT02648997 \\
\hline $\begin{array}{l}\text { Vismodegib and FAK Inhibi- } \\
\text { tor GSK2256098 in Treating } \\
\text { Patients With Progressive } \\
\text { Meningiomas }\end{array}$ & $\begin{array}{l}\text { Vismodegib, } \\
\text { GSK2256098 }\end{array}$ & II & 69 & $\begin{array}{l}\text { Alliance for Clinical Trials in Oncology, } \\
\text { National Cancer Institute, GlaxoSmith- } \\
\text { Kline, Genentech Inc., Brain Science } \\
\text { Foundation }\end{array}$ & $\begin{array}{r}\text { August } \\
2019\end{array}$ & NCT02523014 \\
\hline $\begin{array}{l}\text { Phase II Trial of Pembrolizumab } \\
\text { in Recurrent or Residual High } \\
\text { Grade Meningioma }\end{array}$ & Pembrolizumab & II & 26 & $\begin{array}{l}\text { Massachusetts General Hospital, Merck } \\
\text { Sharp \& Dohme Corp. }\end{array}$ & $\begin{array}{l}\text { March } \\
2021\end{array}$ & NCT03279692 \\
\hline $\begin{array}{l}\text { Trial of Selumetinib in Patients } \\
\text { With Neurofibromatosis Type II } \\
\text { Related Tumors (SEL-TH-1601) }\end{array}$ & Selumetinib & II & 34 & $\begin{array}{l}\text { Children's Hospital Medical Center, } \\
\text { AstraZeneca }\end{array}$ & May 2020 & NCT03095248 \\
\hline $\begin{array}{l}\text { Immune Checkpoint Inhibitor } \\
\text { Nivolumab in People With Select } \\
\text { Rare CNS Cancers }\end{array}$ & Nivolumab & II & 180 & National Cancer Institute & $\begin{array}{l}\text { December } \\
2021\end{array}$ & NCT03173950 \\
\hline
\end{tabular}

A report of the PD-1 inhibitor nivolumab for lung cancer in a patient with concurrent meningioma demonstrated a $24 \%$ radiographic volume reduction in the meningioma. ${ }^{20}$ Trials of nivolumab (NCT03173950, http://www. clinicaltrials.gov) and another PD-1 inhibitor, pembrolizumab (NCT03279692, http://www.clinicaltrials.gov), for meningioma are currently recruiting participants.

\section{Combinatorial Pharmacological Therapies}

Targeted therapies have great potential in personalized medicine by allowing each patient's mutagenic profile to guide their treatment. An inherent limitation to this paradigm is the "one mutation, one drug" assumption. Intratumoral genomic heterogeneity renders subpopulations of tumor cells immune to therapies targeted to alterations found in neighboring cell populations, resulting in the subsequent outgrowth of these resistant clones. Combinatorial therapies mitigate this problem by targeting multiple pathways simultaneously. The intratumoral genomic heterogeneity observed in recurrent meningioma underlies the need for therapeutic approaches that efficaciously target different subpopulations.

Authors of recent studies have examined the safety and efficacy of combinatorial therapy in meningioma with promising results. In a phase II trial of hydroxyurea and imatinib for patients with progressive or recurrent meningioma, the majority of cases demonstrated stable disease, though no cases showed a positive radiological response. ${ }^{61}$ The combination was well tolerated and PFS6 for all cases was $61.9 \%$. A randomized phase II trial testing the same combinatorial therapy was prematurely concluded because of slow enrollment, although all patients who enrolled demonstrated stable disease. ${ }^{49} \mathrm{~A}$ phase I/II trial of hydroxyurea and verapamil, a calcium-channel antagonist that enhances hydroxyurea's cytostatic effect in in vitro and in vivo models of meningioma, demonstrated side effects in $86 \%$ of patients and a median PFS and PFS6 of 8 months and $85 \%$, respectively, in refractory meningioma. ${ }^{21}$

\section{Current Trials}

Currently, there are 8 active, enrolling trials assessing novel medical strategies for meningioma, focusing on cytotoxic chemotherapy, targeted therapy, combinatorial therapy, and immunotherapy (Table 3 ). These include phase 0 trials of AR-42 (NCT02282917) and the mTOR inhibitor everolimus (NCT01880749, not recruiting). AR-42 will gauge the efficacy of epigenomic manipulation in meningioma treatment, while everolimus will target the mTOR pathway, which has been shown to be overactive in some meningiomas. Currently enrolling phase II trials include the cyclin/CDK inhibitor ribociclib (NCT02933736); the hedgehog pathway inhibitor vismodegib and the focal adhesion kinase inhibitor GSK2256098 (NCT02523014); the MEK1 inhibitor selumetinib (NCT03095248); the PD-1 
inhibitors nivolumab (NCT03173950) and pembrolizumab (NCT03279692); and a combinatorial regimen consisting of everolimus and octreotide (NCT02333565, status unknown).

Prior trials have demonstrated that no individual agent or class of agents is likely to produce a favorable response in all recurrent and progressive meningiomas. Rather, different therapeutics will probably be more efficacious for certain tumors depending on the genomic makeup of the tumor and the local immune microenvironment among other factors. The enrolling trials on ribociclib, vismodegib, and selumetinib incorporate genomic data for inclusion criteria, which may provide guidance in predicting biological subsets of meningiomas that will respond favorably.

\section{Future Directions}

Expanding knowledge of meningioma biology is powering the development of novel therapeutics to challenge this disease. Genomics and epigenetic signatures may also improve prognostication and trial stratification. Evolving quantitative radiomic characterizations of meningioma may provide additional tumor stratification tools and upfront prediction of tumor behavior on initial diagnosis. Finally, acknowledging the cellular heterogeneity of meningioma conferred by cancer stem cells provides a parallel avenue for therapeutic discoveries in multidrug-resistant meningioma.

\section{Conclusions}

Few options exist to medically manage refractory and progressive cases of meningioma. Advances in molecular biology and genomics have led to the development of novel molecular inhibitors that can target aberrantly expressed oncogenic and immunomodulatory molecules. Emerging trials for meningioma are beginning to integrate genomic inclusion criteria, with hope to refine future clinical outcomes within the precision medicine paradigm.

\section{References}

1. Abedalthagafi M, Bi WL, Aizer AA, Merrill PH, Brewster R, Agarwalla PK, et al: Oncogenic PI3K mutations are as common as AKT1 and SMO mutations in meningioma. Neuro Oncol 18:649-655, 2016

2. Alanin MC, Klausen C, Caye-Thomasen P, Thomsen C, Fugleholm K, Poulsgaard L, et al: Effect of bevacizumab on intracranial meningiomas in patients with neurofibromatosis type $2-$ a retrospective case series. Int J Neurosci 126:1002-1006, 2015

3. Andrae N, Kirches E, Hartig R, Haase D, Keilhoff G, Kalinski T, et al: Sunitinib targets PDGF-receptor and Flt3 and reduces survival and migration of human meningioma cells. Eur J Cancer 48:1831-1841, 2012

4. Bi WL, Greenwald NF, Abedalthagafi M, Wala J, Gibson WJ, Agarwalla PK, et al: Genomic landscape of high-grade meningiomas. NPJ Genom Med 2:15, 2017

5. Bi WL, Wu WW, Santagata S, Reardon DA, Dunn IF: Checkpoint inhibition in meningiomas. Immunotherapy 8:721731, 2016

6. Boetto J, Bielle F, Sanson M, Peyre M, Kalamarides M: SMO mutation status defines a distinct and frequent molecular subgroup in olfactory groove meningiomas. Neuro Oncol 19:345-351, 2017
7. Brastianos PK, Horowitz PM, Santagata S, Jones RT, McKenna A, Getz G, et al: Genomic sequencing of meningiomas identifies oncogenic SMO and AKT1 mutations. Nat Genet 45:285-289, 2013

8. Burns SS, Akhmametyeva EM, Oblinger JL, Bush ML, Huang J, Senner V, et al: Histone deacetylase inhibitor AR42 differentially affects cell-cycle transit in meningeal and meningioma cells, potently inhibiting NF2-deficient meningioma growth. Cancer Res 73:792-803, 2013

9. Chamberlain MC: Adjuvant combined modality therapy for malignant meningiomas. J Neurosurg 84:733-736, 1996

10. Chamberlain MC: Hydroxyurea for recurrent surgery and radiation refractory high-grade meningioma. J Neurooncol 107:315-321, 2012

11. Chamberlain MC: IFN- $\alpha$ for recurrent surgery- and radiation-refractory high-grade meningioma: a retrospective case series. CNS Oncol 2:227-235, 2013

12. Chamberlain MC, Glantz MJ: Interferon-alpha for recurrent World Health Organization grade 1 intracranial meningiomas. Cancer 113:2146-2151, 2008

13. Chamberlain MC, Johnston SK: Hydroxyurea for recurrent surgery and radiation refractory meningioma: a retrospective case series. J Neurooncol 104:765-771, 2011

14. Chamberlain MC, Tsao-Wei DD, Groshen S: Salvage chemotherapy with CPT-11 for recurrent meningioma. J Neurooncol 78:271-276, 2006

15. Chamberlain MC, Tsao-Wei DD, Groshen S: Temozolomide for treatment-resistant recurrent meningioma. Neurology 62:1210-1212, 2004

16. Cheng G, Zhang L, Lv W, Dong C, Wang Y, Zhang J: Overexpression of cyclin D1 in meningioma is associated with malignancy grade and causes abnormalities in apoptosis, invasion and cell cycle progression. Med Oncol 32:439, 2015

17. Clark VE, Erson-Omay EZ, Serin A, Yin J, Cotney J, Ozduman K, et al: Genomic analysis of non-NF2 meningiomas reveals mutations in TRAF7, KLF4, AKT1, and SMO. Science 339: 1077-1080, 2013

18. Fuentes S, Chinot O, Dufour H, Paz-Paredes A, Métellus P, Barrie-Attarian M, et al: [Hydroxyurea treatment for unresectable meningioma.] Neurochirurgie 50:461-467, 2004 (Fr)

19. García-Luna PP, Relimpio F, Pumar A, Pereira JL, Leal-Cerro A, Trujillo F, et al: Clinical use of octreotide in unresectable meningiomas. A report of three cases. J Neurosurg Sci 37:237-241, 1993

20. Gelerstein E, Berger A, Jonas-Kimchi T, Strauss I, Kanner AA, Blumenthal DT, et al: Regression of intracranial meningioma following treatment with nivolumab: Case report and review of the literature. J Clin Neurosci 37:51-53, 2017

21. Gerlinger M, Rowan AJ, Horswell S, Math M, Larkin J, Endesfelder D, et al: Intratumor heterogeneity and branched evolution revealed by multiregion sequencing. N Engl J Med 366: $883-892,2012$

22. Goldman CK, Bharara S, Palmer CA, Vitek J, Tsai JC, Weiss $\mathrm{HL}$, et al: Brain edema in meningiomas is associated with increased vascular endothelial growth factor expression. Neurosurgery 40:1269-1277, 1997

23. Goodwin JW, Crowley J, Eyre HJ, Stafford B, Jaeckle KA, Townsend JJ: A phase II evaluation of tamoxifen in unresectable or refractory meningiomas: a Southwest Oncology Group study. J Neurooncol 15:75-77, 1993

24. Graillon T, Romano D, Defilles C, Saveanu A, Mohamed A, Figarella-Branger D, et al: Octreotide therapy in meningiomas: in vitro study, clinical correlation, and literature review. J Neurosurg 127:660-669, 2017

25. Grunberg SM, Weiss MH, Russell CA, Spitz IM, Ahmadi J, Sadun A, et al: Long-term administration of mifepristone (RU486): clinical tolerance during extended treatment of meningioma. Cancer Invest 24:727-733, 2006 
26. Grunberg SM, Weiss MH, Spitz IM, Ahmadi J, Sadun A, Russell CA, et al: Treatment of unresectable meningiomas with the antiprogesterone agent mifepristone. J Neurosurg 74:861-866, 1991

27. Grund S, Schittenhelm J, Roser F, Tatagiba M, Mawrin C, Kim YJ, et al: The microglial/macrophagic response at the tumour-brain border of invasive meningiomas. Neuropathol Appl Neurobiol 35:82-88, 2009

28. Gunel M: Meningioma driver mutations determine their anatomical site of origin. Neurosurgery 63 (Suppl 1):185, 2016 (Abstract)

29. Hahn BM, Schrell UM, Sauer R, Fahlbusch R, Ganslandt O, Grabenbauer GG: Prolonged oral hydroxyurea and concurrent $3 \mathrm{~d}$-conformal radiation in patients with progressive or recurrent meningioma: results of a pilot study. J Neurooncol 74:157-165, 2005

30. Han SJ, Reis G, Kohanbash G, Shrivastav S, Magill ST, Molinaro AM, et al: Expression and prognostic impact of immune modulatory molecule PD-L1 in meningioma. J Neurooncol 130:543-552, 2016

31. Harmancı AS, Youngblood MW, Clark VE, Coşkun S, Henegariu O, Duran D, et al: Integrated genomic analyses of de novo pathways underlying atypical meningiomas. Nat Commun 8:14433, 2017

32. Horak P, Wöhrer A, Hassler M, Hainfellner J, Preusser M, Marosi C: Imatinib mesylate treatment of recurrent meningiomas in preselected patients: a retrospective analysis. J Neurooncol 109:323-330, 2012

33. Ji Y, Rankin C, Grunberg S, Sherrod AE, Ahmadi J, Townsend JJ, et al: Double-blind phase III randomized trial of the antiprogestin agent mifepristone in the treatment of unresectable meningioma: SWOG S9005. J Clin Oncol 33:4093-4098, 2015

34. Johnson DR, Kimmel DW, Burch PA, Cascino TL, Giannini $\mathrm{C}, \mathrm{Wu} \mathrm{W}$, et al: Phase II study of subcutaneous octreotide in adults with recurrent or progressive meningioma and meningeal hemangiopericytoma. Neuro Oncol 13:530-535, 2011

35. Johnson MD, Okediji E, Woodard A: Transforming growth factor-beta effects on meningioma cell proliferation and signal transduction pathways. J Neurooncol 66:9-16, 2004

36. Johnson MD, Shaw AK, O'Connell MJ, Sim FJ, Moses HL: Analysis of transforming growth factor $\beta$ receptor expression and signaling in higher grade meningiomas. J Neurooncol 103:277-285, 2011

37. Kaba SE, DeMonte F, Bruner JM, Kyritsis AP, Jaeckle KA, Levin V, et al: The treatment of recurrent unresectable and malignant meningiomas with interferon alpha-2B. Neurosurgery 40:271-275, 1997

38. Kaley TJ, Wen P, Schiff D, Ligon K, Haidar S, Karimi S, et al: Phase II trial of sunitinib for recurrent and progressive atypical and anaplastic meningioma. Neuro Oncol 17:116121,2015

39. Karsy M, Hoang N, Barth T, Burt L, Dunson W, Gillespie DL, et al: Combined hydroxyurea and verapamil in the clinical treatment of refractory meningioma: human and orthotopic xenograft studies. World Neurosurg 86:210-219, 2016

40. Kim MS, Yu DW, Jung YJ, Kim SW, Chang CH, Kim OL: Long-term follow-up result of hydroxyurea chemotherapy for recurrent meningiomas. J Korean Neurosurg Soc 52:517522,2012

41. Koper JW, Zwarthoff EC, Hagemeijer A, Braakman R, Avezaat CJ, Bergström M, et al: Inhibition of the growth of cultured human meningioma cells by recombinant interferonalpha. Eur J Cancer 27:416-419, 1991

42. Koschny R, Krupp W, Xu LX, Mueller WC, Bauer M, Sinn $\mathrm{P}$, et al: WHO grade related expression of TRAIL-receptors and apoptosis regulators in meningioma. Pathol Res Pract 211:109-116, 2015

43. Lee SH, Lee YS, Hong YG, Kang CS: Significance of COX-2 and VEGF expression in histopathologic grading and invasiveness of meningiomas. APMIS 122:16-24, 2014

44. Linggood RM, Hsu DW, Efird JT, Pardo FS: TGF alpha expression in meningioma-tumor progression and therapeutic response. J Neurooncol 26:45-51, 1995

45. Lou E, Sumrall AL, Turner S, Peters KB, Desjardins A, Vredenburgh JJ, et al: Bevacizumab therapy for adults with recurrent/progressive meningioma: a retrospective series. J Neurooncol 109:63-70, 2012

46. Marincek N, Radojewski P, Dumont RA, Brunner P, MüllerBrand J, Maecke HR, et al: Somatostatin receptor-targeted radiopeptide therapy with 90 Y-DOTATOC and $177 \mathrm{Lu}-$ DOTATOC in progressive meningioma: long-term results of a phase II clinical trial. J Nucl Med 56:171-176, 2015

47. Markwalder TM, Seiler RW, Zava DT: Antiestrogenic therapy of meningiomas - a pilot study. Surg Neurol 24:245-249, 1985

48. Mason WP, Gentili F, Macdonald DR, Hariharan S, Cruz CR, Abrey LE: Stabilization of disease progression by hydroxyurea in patients with recurrent or unresectable meningioma. $\mathbf{J}$ Neurosurg 97:341-346, 2002

49. Mazza E, Brandes A, Zanon S, Eoli M, Lombardi G, Faedi M, et al: Hydroxyurea with or without imatinib in the treatment of recurrent or progressive meningiomas: a randomized phase II trial by Gruppo Italiano Cooperativo di Neuro-Oncologia (GICNO). Cancer Chemother Pharmacol 77:115120, 2016

50. Mei Y, Bi WL, Greenwald NF, Agar NY, Beroukhim R, Dunn GP, et al: Genomic profile of human meningioma cell lines. PLoS One 12:e0178322, 2017

51. Narla S, Uppin MS, Saradhi MV, Sahu BP, Purohit AK, Sundaram C: Assessment of expression of epidermal growth factor receptor and p53 in meningiomas. Neurol India 62:37-41, 2014

52. Nayak L, Iwamoto FM, Rudnick JD, Norden AD, Lee EQ, Drappatz J, et al: Atypical and anaplastic meningiomas treated with bevacizumab. J Neurooncol 109:187-193, 2012

53. Newton HB, Scott SR, Volpi C: Hydroxyurea chemotherapy for meningiomas: enlarged cohort with extended follow-up. Br J Neurosurg 18:495-499, 2004

54. Newton HB, Slivka MA, Stevens C: Hydroxyurea chemotherapy for unresectable or residual meningioma. J Neurooncol 49:165-170, 2000

55. Norden AD, Ligon KL, Hammond SN, Muzikansky A, Reardon DA, Kaley TJ, et al: Phase II study of monthly pasireotide LAR (SOM230C) for recurrent or progressive meningioma. Neurology 84:280-286, 2015

56. Nunes FP, Merker VL, Jennings D, Caruso PA, di Tomaso E, Muzikansky A, et al: Bevacizumab treatment for meningiomas in NF2: a retrospective analysis of 15 patients. PLoS One 8:e59941, 2013

57. Oblinger JL, Burns SS, Huang J, Pan L, Ren Y, Shen R, et al: Overexpression of eIF4F components in meningiomas and suppression of meningioma cell growth by inhibiting translation initiation. Exp Neurol 299:299-307, 2018

58. Peyre M, Salaud C, Clermont-Taranchon E, Niwa-Kawakita M, Goutagny S, Mawrin C, et al: PDGF activation in PGDSpositive arachnoid cells induces meningioma formation in mice promoting tumor progression in combination with $\mathrm{Nf} 2$ and Cdkn2ab loss. Oncotarget 6:32713-32722, 2015

59. Raheja A, Colman H, Palmer CA, Couldwell WT: Dramatic radiographic response resulting in cerebrospinal fluid rhinorrhea associated with sunitinib therapy in recurrent atypical meningioma: case report. J Neurosurg 127:965-970, 2017

60. Raizer JJ, Grimm SA, Rademaker A, Chandler JP, Muro K, Helenowski I, et al: A phase II trial of PTK787/ZK 222584 in recurrent or progressive radiation and surgery refractory meningiomas. J Neurooncol 117:93-101, 2014

61. Reardon DA, Norden AD, Desjardins A, Vredenburgh JJ, 
Herndon JE II, Coan A, et al: Phase II study of Gleevec ${ }^{\circledR}$ plus hydroxyurea (HU) in adults with progressive or recurrent meningioma. J Neurooncol 106:409-415, 2012

62. Rosenthal MA, Ashley DL, Cher L: Treatment of high risk or recurrent meningiomas with hydroxyurea. J Clin Neurosci 9:156-158, 2002

63. Sanford M, Scott LJ: Gefitinib: a review of its use in the treatment of locally advanced/metastatic non-small cell lung cancer. Drugs 69:2303-2328, 2009

64. Schrell UM, Rittig MG, Anders M, Koch UH, Marschalek R, Kiesewetter F, et al: Hydroxyurea for treatment of unresectable and recurrent meningiomas. II. Decrease in the size of meningiomas in patients treated with hydroxyurea. J Neurosurg 86:840-844, 1997

65. Schulz C, Mathieu R, Kunz U, Mauer UM: Treatment of unresectable skull base meningiomas with somatostatin analogs. Neurosurg Focus 30(5):E11, 2011

66. Shankar GM, Abedalthagafi M, Vaubel RA, Merrill PH, Nayyar N, Gill CM, et al: Germline and somatic BAP1 mutations in high-grade rhabdoid meningiomas. Neuro Oncol 19:535-545, 2017

67. Shih KC, Chowdhary S, Rosenblatt P, Weir AB III, Shepard GC, Williams JT, et al: A phase II trial of bevacizumab and everolimus as treatment for patients with refractory, progressive intracranial meningioma. J Neurooncol 129:281-288, 2016

68. Simó M, Argyriou AA, Macià M, Plans G, Majós C, Vidal N, et al: Recurrent high-grade meningioma: a phase II trial with somatostatin analogue therapy. Cancer Chemother Pharmacol 73:919-923, 2014

69. Todo T, Adams EF, Fahlbusch R, Dingermann T, Werner H: Autocrine growth stimulation of human meningioma cells by platelet-derived growth factor. J Neurosurg 84:852-859, 1996

70. Tuchen M, Wilisch-Neumann A, Daniel EA, Baldauf L, Pachow D, Scholz J, et al: Receptor tyrosine kinase inhibition by regorafenib/sorafenib inhibits growth and invasion of meningioma cells. Eur J Cancer 73:9-21, 2017

71. Weller M, Roth P, Sahm F, Burghardt I, Schuknecht B, Rushing EJ, et al: Durable control of metastatic AKT1-mutant WHO Grade 1 meningothelial meningioma by the AKT inhibitor, AZD5363. J Natl Cancer Inst 109:1-4, 2017
72. Wen PY, Quant E, Drappatz J, Beroukhim R, Norden AD: Medical therapies for meningiomas. J Neurooncol 99:365378, 2010

73. Wen PY, Yung WK, Lamborn KR, Norden AD, Cloughesy TF, Abrey LE, et al: Phase II study of imatinib mesylate for recurrent meningiomas (North American Brain Tumor Consortium study 01-08). Neuro Oncol 11:853-860, 2009

74. Weston GJ, Martin AJ, Mufti GJ, Strong AJ, Gleeson MJ: Hydroxyurea treatment of meningiomas: a pilot study. Skull Base 16:157-160, 2006

75. Yang SY, Xu GM: Expression of PDGF and its receptor as well as their relationship to proliferating activity and apoptosis of meningiomas in human meningiomas. J Clin Neurosci 8 (Suppl 1):49-53, 2001

\section{Disclosures}

The authors report no conflict of interest concerning the materials or methods used in this study or the findings specified in this paper.

\section{Author Contributions}

Conception and design: all authors. Acquisition of data: all authors. Analysis and interpretation of data: all authors. Drafting the article: all authors. Critically revising the article: all authors. Reviewed submitted version of manuscript: all authors. Approved the final version of the manuscript on behalf of all authors: Dunn. Administrative/technical/material support: all authors. Study supervision: all authors.

\section{Supplemental Information \\ Previous Presentations}

Portions of this paper were presented in poster format at the 2016 New England Neurosurgical Society conference.

\section{Correspondence}

Ian F. Dunn: Brigham and Women's Hospital, Boston, MA. idunn@partners.org. 